\section{USE OF MEDICATIONS FOR TYPE 2 DIABETES MELLITUS IN THE BRAZIL'S FAMILY HEALTH STRATEGY: GENDER DIFFERENCES}

\author{
Rinaldo Eduardo Machado de Oliveira ${ }^{1}$, Anderson Soares da Silva ${ }^{1}$, \\ Julieta Ueta² ${ }^{2}$ Laercio Joel Franco ${ }^{1}$
}

\begin{abstract}
Introduction: The medications are the main therapeutic inputs in the treatment of type 2 diabetes mellitus. When properly used, they allow disease control and reduction of morbidity and mortality, resulting in improvements in quality of life. Thus, the purpose of this article is to characterize the use of medications for type 2 diabetes mellitus with emphasis on gender differences.
\end{abstract}

Methods: A cross-sectional study performed in Family Health Units in Ribeirão Preto, São Paulo, Brazil, with 100 men and 100 women. Sociodemographic characteristics, clinical data, lifestyle and use of medications were the variables of interest.

Results: Mean number of diabetes medications referred by study participants was $1.6(S D=0.7)$ for women and $1.5(S D=0.6)$ for men $(p=0.40)$. The use of metformin was mentioned by $70 \%$ of women and $65 \%$ of men, and adverse reactions were reported by $15 \%$ of women and $2 \%$ of men $(p<0.01)$. Medications were obtained mainly from public health system pharmacies in both genders.

Conclusions: Gender differences in the use of diabetes medications were found in reported adverse reactions, with more cases among women.

Keywords: Drug therapy; pharmacoepidemiology; pharmaceutical care; chronic disease; diabetes mellitus; family health strategy

Noncommunicable diseases (NCDs) are a global health problem, and diabetes mellitus (DM) is a major focus of concern ${ }^{1}$. In 2014, the estimated DM prevalence was $8.5 \%$ worldwide ${ }^{2}$. The scenario in Brazil is worrisome. The estimated DM prevalence in the country was $5.5 \%$ in 2006 and reached $8.9 \%$ in 2016 , which represents a $61.8 \%$ increase in the number of people diagnosed with DM in the last 10 years. The disease affects $9.9 \%$ of women and $7.8 \%$ of $\operatorname{men}^{3,4}$.

Type 2 DM accounts for $90-95 \%$ of the cases and is characterized by deficient insulin action and secretion and poor regulation of hepatic glucose production ${ }^{5,6}$. Type $2 \mathrm{DM}$ associated with other NCDs is responsible for high proportions of mortality, costs with outpatient procedures, use of medications and hospital admissions $\mathbf{s}^{7,8}$.

Prevention of complications related to type $2 \mathrm{DM}$ is crucial. Disease control involves changes in lifestyle, including adoption of a diet plan and regular practice of physical exercise, as well as the use of medications ${ }^{5,6}$.

Medications play an important role in diabetes care. The current drugs to treat type $2 \mathrm{DM}$ have different safety and effectiveness profiles. Besides, they may have effects on insulin deficiency or resistance or on intestinal glucose absorption ${ }^{5,6}$. There are also drugs that act on the reabsorption of glucose in the kidneys ${ }^{5,6}$. In evidence-based practice, antidiabetic drugs may be prescribed as monotherapy or combination therapy depending on the characteristics of the patient and the disease. It is known that medications,
Clin Biomed Res. 2018;38(1):17-21

1 Social Medicine Department, School of Medicine of Ribeirão Preto, Universidade de São Paulo (USP). Ribeirão Preto, SP, Brasil.

2 Pharmaceutical Sciences Department, School of Pharmaceutical Sciences of Ribeirão Preto, Universidade de São Paulo (USP). Ribeirão Preto, SP, Brasil.

Corresponding author:

Rinaldo Eduardo Machado de Oliveira rinaldo.eduardo@usp.br

Social Medicine Department, School of Medicine of Ribeirão Preto, Universidade de São Paulo (USP)

Avenida Bandeirantes, 3900.

14049-900, Ribeirão Preto, SP, Brasil 
when properly used, are able to control diabetes and reduce morbidity and mortality, resulting in improved quality of life ${ }^{9,10}$.

The literature shows that there are behavioral differences between men and women in diabetes care. Women are more alert to signs and symptoms and cherish self-care. Men usually seek health services in extreme situations or when they are unable to work ${ }^{8,9}$.

There are few studies on the use of medications to treat DM in the Family Health Strategy (FHS) focusing on the differences between men and women. Thus, the aim of the present study was to characterize the use of medications for type $2 \mathrm{DM}$ with emphasis on gender differences.

\section{METHODS}

This is a cross-sectional study conducted at Family Health Units (FHUs) of the Western Sanitary District in Ribeirão Preto, São Paulo, Brazil, with adult patients diagnosed with type $2 \mathrm{DM}$ and using medications to treat the disease. Patients with cognitive deficit or communication difficulty, bedridden patients, those who depended on caregivers, and those with history of surgeries or admissions in the 3 months prior to the interview were excluded.

The present study originates from the following master's dissertation: "Adherence to type 2 diabetes mellitus pharmacotherapy at the Family Healthcare Strategy: a gender perspective". The sample was calculated considering a $75 \%$ frequency of adherence to drug therapy, a margin of error of $5 \%$, and an alpha of $5 \%$. The sample size was then estimated in 200 participants, which were divided proportionally to the number of patients with DM who were registered in six FHUs of the Western Sanitary District. The sample was stratified into four groups as follows: I - 50 female patients with type $2 \mathrm{DM}$ aged 18-59 years; II - 50 female patients with type 2 DM aged 60 years or more; III - 50 male patients with type 2 DM aged $18-59$ years; and IV - 50 male patients with type $2 \mathrm{DM}$ aged 60 years or more. A pilot test was performed in a non-registered $\mathrm{FHU}$ with 10 participants, who were not included in the final study sample.

This was a convenience sample, and the quota of each $\mathrm{FHU}$ was filled as patients sought the service. At the beginning of the interview, prescriptions, package inserts, blister packs and boxes of the medications used by each patient were requested. The instrument for data collection consisted of a questionnaire on sociodemographic data, health care, use of medications, and access to and use of health services. The Brief Medication Questionnaire was used to evaluate medications used, adherence and adverse reactions ${ }^{11}$. Data collection was conducted between November 2015 and April 2016.

In descriptive data analysis, frequencies and percentages were obtained for qualitative variables, and measures of dispersion for quantitative variables. The Pearson's chi-square test was used to assess the association between variables of interest. The Student's t-test was used to compare means. When necessary, the significance level was set at $p<0.05$. Statistical analyses were performed using $\mathrm{SAS}^{\circledR}$ version 9.2 .

The research project was approved by the local Research Ethics Committee with protocol number 47811515.9.0000.5414. All participants signed an informed consent form.

\section{RESULTS}

The study sample was characterized by low income and low level of education. Regarding socioeconomic status, $43 \%$ of women and $53 \%$ of men were categorized as classes D/E according to the Brazilian Economic Classification Criterion ${ }^{12}$. Regarding level of education, $77 \%$ of women and $78 \%$ of men reported 8 or less years of schooling. The mean age was 63.9 years $(S D=13.7)$ in women and 59.5 years $(S D=13.9)$ in men. Most men and women reported being white (66\% for both) and married ( $63 \%$ of women and $65 \%$ of men). Most men reported being employed/self-employed (57\%) and most women reported being retired/pensioner (45\%).

The mean number of medications used to treat DM was $1.6(S D=0.7)$ in women and $1.5(S D=0.6)$ in men $(p=0.40)$. Table 1 shows self-reported medications used to treat DM with a prevalence of metformin monotherapy in both genders. Metformin was the oral antidiabetic drug (OAD) most mentioned as a potential cause of adverse reactions, reported by $15 \%$ of women and $2 \%$ of men $(p<0.01$ ) (Table 2 ). Diarrhea was reported as the main symptom by $13 \%$ of women and $1 \%$ of men (Table 3 ).

Medications were mostly or partially obtained from public health system pharmacies by $65 \%$ of women

Table 1: Self-reported medications for the treatment of type 2 diabetes mellitus in Family Health Units according to gender. Ribeirão Preto, SP, 2016.

\begin{tabular}{lcc}
\hline \multicolumn{1}{c}{ Medications } & $\begin{array}{c}\text { Women } \\
\mathbf{n = 1 0 0}\end{array}$ & $\begin{array}{c}\text { Men } \\
\mathbf{n = 1 0 0}\end{array}$ \\
\hline Metformin alone & 35 & 33 \\
Sulfonylurea alone & 12 & 14 \\
Insulin alone & 10 & 16 \\
Metformin + sulfonylurea & 22 & 18 \\
Oral antidiabetic drug + insulin & 17 & 17 \\
Others & 4 & 2 \\
\hline
\end{tabular}


Table 2: Self-reported medications that caused adverse reactions according to gender. Ribeirão Preto, SP, 2016.

\begin{tabular}{lcc}
\hline $\begin{array}{c}\text { Medications that caused } \\
\text { adverse reactions }\end{array}$ & $\begin{array}{c}\text { Women } \\
\mathbf{n = 1 0 0}\end{array}$ & $\begin{array}{c}\text { Men } \\
\mathbf{n = 1 0 0}\end{array}$ \\
\hline Metformin & 15 & 2 \\
Insulin & 2 & 1 \\
Saxagliptin + metformin & 1 & 0 \\
Dapagliflozin & 1 & 0 \\
\hline
\end{tabular}

Table 3: Adverse drug reactions reported by study participants according to gender. Ribeirão Preto, SP, 2016.

\begin{tabular}{lcc}
\hline \multicolumn{1}{c}{ Adverse drug reactions } & $\begin{array}{c}\text { Women } \\
\mathbf{n = 1 0 0}\end{array}$ & $\begin{array}{c}\text { Men } \\
\mathbf{n = 1 0 0}\end{array}$ \\
\hline Diarrhea & 13 & 1 \\
Hypoglycemia & 2 & 0 \\
Taste of blood in the mouth & 1 & 1 \\
Others & 3 & 1 \\
\hline
\end{tabular}

Table 4: Sources of medication acquisition for the treatment of type 2 diabetes mellitus reported by the study participants in Family Health Units according to gender. Ribeirão Preto, SP, 2016.

\begin{tabular}{lcc}
\hline Sources of medication acquisition & $\begin{array}{c}\text { Women } \\
\mathbf{n = 1 0 0}\end{array}$ & $\begin{array}{c}\text { Men } \\
\mathbf{n}=\mathbf{1 0 0}\end{array}$ \\
\hline Public health system pharmacy & 55 & 60 \\
Brazilian Popular Pharmacy Program & 29 & 26 \\
Commercial pharmacy & 4 & 3 \\
Public health system pharmacy + & 10 & 11 \\
Brazilian Popular Pharmacy Program & & \\
Public health system pharmacy + & 2 & 0 \\
Commercial pharmacy & & \\
\hline
\end{tabular}

and $71 \%$ of men. The Brazilian Popular Pharmacy Program (BPPP), a government program of co-payment in the private system, was used by $29 \%$ of women and $26 \%$ of men to obtain their medications (Table 4 ).

\section{DISCUSSION}

This study included FHU patients who used at least one medication to treat type $2 \mathrm{DM}$. The results of the 2013 Brazilian National Health Survey showed that $80.2 \%$ of the participants who reported having diabetes used medications, with higher proportion in the South-East region and lower proportion in the North region. In addition, no significant differences were found between genders according to the point estimates for the Brazilian regions ${ }^{11}$.

In the present study, the mean number of medications used to treat type 2 DM was higher among women. However, there were no statistically significant differences in the comparison of means between genders. This finding differs from a study with patients with type 2 DM in a Primary Health
Care Unit in ljuí, Rio Grande do Sul, in which the mean number of medications was $2.2(S D=1.0)$ in women and $2.7(\mathrm{SD}=0.8)$ in men $^{13}$.

Metformin was the most mentioned medication by both genders. Current guidelines of the Brazilian Diabetes Association and the American Diabetes Association are consistent in terms of metformin prescription, associated with changes in lifestyle, for patients recently diagnosed with type $2 \mathrm{DM}^{5,6}$. However, monotherapy may not be enough to obtain glycemic control, and it is often necessary to combine other OADs according to disease progression ${ }^{10}$.

The literature suggests caution in the prolonged use of metformin, which may cause vitamin B12 deficiency. One of the likely causes of diabetic neuropathy is associated with this type of deficiency ${ }^{14}$. Also, although metformin has low potential for drug interaction, a careful evaluation should be performed when using it concomitantly with medications that cause harm to the renal function ${ }^{15}$.

A pharmacotherapy study of type $2 \mathrm{DM}$ conducted in a FHU in João Pessoa, Paraíba, found that $96.9 \%$ of men (who represented $50 \%$ of the sample) used $\mathrm{OAD}$ and the other ones used insulin alone. Of the participants who used OAD, $38.7 \%$ used metformin combined with glibenclamide, $32.3 \%$ metformin alone, $19.4 \%$ glibenclamide alone, $6.5 \%$ metformin combined with glimepiride, and $3.2 \%$ glimepiride alone. In addition, $12.5 \%$ of the study participants reported adverse reaction and attributed it to the use of OAD. The listed symptoms were stomach pain/discomfort or headache, and all patients who reported these used metformin. The authors did not specify the proportion of adverse reaction according to gender ${ }^{16}$.

Potential adverse reactions to metformin were reported by both genders in the present study, predominantly in women. The literature shows that this OAD may cause abdominal discomfort, diarrhea and headache. It also shows that extended-release formulations of this medication may cause less adverse events ${ }^{5,6}$. A randomized clinical trial conducted in 27 health centers in the United States with 2,155 patients with type 2 DM divided into 2 groups - metformin and placebo - showed that women in the metformin group reported more adverse reactions $(p=0.002)^{17}$.

In the present study, the main source of medications were the public health system pharmacies, followed by the BPPP, in both genders. Data from the 2014 Brazilian National Survey on Access, Utilization and Promotion of Rational Use of Medications showed that $78.6 \%$ (95\% Cl: 75.6-81.3) of diabetes medications were obtained free of charge ${ }^{18}$.

The 2013 National Health Survey showed that $57.4 \%$ of patients with DM used at least one medication 
provided by the BPPP. Higher proportions of acquisition through BPPP were found in black patients $(69.4 \%)$ and in patients with lower level of education ( $\leq 8$ years of schooling) (63.9\%). Regarding gender, even without statistically significant differences, women from most regions tended to obtain more diabetes medications from the BPPP than men ${ }^{19}$.

The present study contributed to expand the knowledge on type $2 \mathrm{DM}$ pharmacotherapy, particularly in the FHS. Data presented here provide reflections to health care and chronic disease management. However, some limitations should be considered. Information on the continuous use of type 2 DM medications was collected. Conversely, information on home use of medications to treat other diseases, as well as on use of medications to treat acute conditions, phytotherapeutic drugs, homeopathic drugs and self-medication, was not collected. Also, pharmacotherapy quality was not assessed. Memory bias when describing medications used and adverse reactions is another limitation of this study. However, prescribed medications were consistent with current guidelines for diabetes treatment ${ }^{5,6}$.

The present study showed a prevalence of monotherapy for the treatment of type $2 \mathrm{DM}$ in both genders. Metformin was the most mentioned OAD and was associated with potential adverse reactions in women more often. Most medications were obtained from public health system pharmacies or through the BPPP. It is worth highlighting the importance of the implementation of actions to promote the rational use of medications considering pharmacotherapy characteristics of men and women with type $2 \mathrm{DM}$ in the FHS.

\section{Conflicts of Interest}

The authors declare no conflicts of interest.

\section{Institution where the study was performed}

School of Medicine of Ribeirão Preto, Universidade de São Paulo.

\section{REFERENCES}

1. Alleyne G, Binagwaho A, Haines $A$, Jahan S, Nugent R, Rojhani $A$, et al. Embedding noncommunicable diseases in the post-2015 development agenda. Lancet. 2013;381(9866):566-74. PMid:23410606. http://dx.doi org/10.1016/S0140-6736(12)61806-6.

2. World Health Organization (WHO). Global report on diabetes. Geneva: WHO; 2016.

3. Iser BPM, Stopa SR, Chueiri PS, Szwarcwald CL, Malta DC, Monteiro $\mathrm{HOC}$, et al. Prevalência de diabetes autorreferido no Brasil: resultados da Pesquisa Nacional de Saúde 2013. Epidemiol Ser Saúde. 2015;24(2):30514. http://dx.doi.org/10.5123/S167949742015000200013

4. Brasil. Ministério da Saúde Secretaria de Vigilância em Saúde. Departamento de Vigilância de Doenças e Agravos não Transmissíveis e Promoção da Saúde. Vigitel Brasil 2016: vigilância de fatores de risco e proteção para doenças crônicas por inquérito telefônico: estimativas sobre frequência e distribuição sociodemográfica de fatores de risco e proteção para doenças crônicas nas capitais dos 26 estados brasileiros e no Distrito Federal em 2016. Brasília: Ministério da Saúde; 2017.
5. Standards of medical care in diabetes 2016. Summary of Revisions. Diabetes Care. 2016;39(Suppl 1):S45. PMid:26696680. http://dx.doi. org/10.2337/dc16-S003.

6. Sociedade Brasileira de Diabetes (SBD). Diretrizes da Sociedade Brasileira de Diabetes 2015-2016. São Paulo: A.C. Farmacêutica; 2016.

7. Malta DC, Silva JB JR. Plano de ações estratégicas para o enfrentamento das doenças crônicas não transmissíveis no Brasil após 3 anos de implantação, 2011-2013. Epidemiol Serv Saúde. 2014;23(3):389-95. http:// dx.doi.org/10.5123/S1679. 49742014000300002.

8. Malta DC, Moura L, Prado RR, Escalante JC, Schmidt MI, Duncan BB. Mortalidade por doenças crônicas não transmissíveis no Brasil e suas regiões, 2000 a 2011. Epidemiol Serv Saúde. 2014;23(4):599-608. http://dx.doi.org/10.5123/S167949742014000400002.

9. Coleman $\mathrm{Cl}$, Limone B, Sobieraj DM, Lee S, Roberts MS, Kaur R, et al. Dosing frequency and medication adherence in chronic disease. $J$ Manag Care Pharm. 2012;18(7):52739. PMid:22971206. http://dx.doi. org/10.18553/jmcp.2012.18.7.527.
10. Maruthur NM, Tseng E, Hutfless S, Wilson LM, Suarez-Cuervo C, Berger $Z$, et al. Diabetes medications as monotherapy or metformin-based combination therapy for type 2 diabetes: a systematic review and meta-analysis. Ann Intern Med. 2016:164(11):740-51. PMid:27088241. http://dx.doi.org/10.7326/M15-2650.

11. Tavares NUL, Costa KS, Mengue SS, Vieira MLFP, Malta DC, Silva JB JR. Uso de medicamentos para tratamento de doenças crônicas não transmissíveis no Brasil: resultados da Pesquisa Nacional de Saúde, 2013. Epidemiol Serv Saúde. 2015;24(2):315-23. http://dx.doi.org/10.5123/S167949742015000200014

12. Associação Brasileira de Empresas de Pesquisa (ABEP). Critério de Classificação Econômica Brasil. São Paulo: ABEP; 2015. [citado 2017 Out]. Disponível em: http://www.abep.orgl

13. Santos FS, Oliveira KR, Colet CF. Adesão ao tratamento medicamentoso pelos portadores de Diabetes Mellitus atendidos em uma Unidade Básica de Saúde no município de ljuí/RS: um estudo exploratório. Rev Cienc Farm Basica Apl. 2010;31:223-7.

14. Chapman LE, Darling AL, Brown JE. Association between metformin and vitamin B12 deficiency in patients with 
type 2 diabetes: A systematic review and meta-analysis. Diabetes Metab. 2016;42(5):316-27. PMid:27130885. http://dx.doi.org/10.1016/j. diabet.2016.03.008.

15. May M, Schindler C. Clinically and pharmacologically relevant interactions of antidiabetic drugs. Ther Adv Endocrinol Metab. 2016;7(2):6983. PMid:27092232. http://dx.doi. org/10.1177/2042018816638050.

16. Nóbrega RC, Batista LM, Moraes LCSL. Análise da farmacoterapia do diabetes mellitus tipo II em uma
Estratégia de Saúde da Família da cidade de João Pessoa-PB. Rev Bras Farm. 2012;93:204-8.

17. Walker EA, Molitch M, Kramer MK, Kahn S, Ma Y, Edelstein S, et al. Adherence to preventive medications: predictors and outcomes in the Diabetes Prevention Program. Diabetes Care. 2006;29(9):19972002. PMid:16936143. http://dx.doi. org/10.2337/dc06-0454.

18. Tavares NUL, Luiza VL, Oliveira MA, Costa KS, Mengue SS, Arrais $\mathrm{PSD}$, et al. Acesso gratuito a medicamentos para tratamento de doenças crônicas no Brasil. Rev Saude Publica. 2016;50(Supl 2):7s. PMid:27982374.

19. Costa KS, Tavares NUL, Mengue SS, Pereira MA, Malta DC, Silva JB JR. Obtenção de medicamentos para hipertensão e diabetes no Programa Farmácia Popular do Brasil: resultados da Pesquisa Nacional de Saúde, 2013. Epidemiol Serv Saúde. 2016;25(1):33-44. PMid:27861676.

Received: Oct 15, 2017 Accepted: Jan 26, 2018 